\title{
Financial Subsidy, Corporate Lifecycle and R\&D Innovation
}

\author{
Ke Yang \\ Jinan University, Guangzhou, China \\ Email: a276656416@126.com
}

How to cite this paper: Yang, K. (2020). Financial Subsidy, Corporate Lifecycle and R\&D Innovation. Modern Economy, 11, 657-668.

https://doi.org/10.4236/me.2020.113049

Received: February 7, 2020

Accepted: March 16, 2020

Published: March 19, 2020

Copyright $\odot 2020$ by author(s) and Scientific Research Publishing Inc. This work is licensed under the Creative Commons Attribution International License (CC BY 4.0).

http://creativecommons.org/licenses/by/4.0/

\begin{abstract}
There is great uncertainty in the effect of financial subsidy on enterprise innovation, which is reflected in the difference in the effects during different lifecycle stages. Based on the theory of financial subsidy's influence on enterprise innovation and the theory of enterprise lifecycle, this paper demonstrates the different effects of financial subsidy on $\mathrm{R} \& \mathrm{D}$ innovation when enterprises are in different lifecycle stages. Moreover, using the data of listed companies in the A-share market of China from 2013 to 2017, the paper finds that there are significant differences in the impact of financial subsidy on enterprise innovation through the fixed effect model and hierarchical multiple regression. Therefore, financial subsidy for enterprise innovation is important and should be differentiated to different life cycle enterprises.
\end{abstract}

\section{Keywords}

Financial Subsidies, R\&D, Innovation, Lifecycle

\section{Introduction}

Financial subsidy has a significant impact on enterprise innovation. Financial subsidy is necessary for enterprise innovation because enterprise $R \& D$ has the property of public goods which may lead to market failure (Schumpeter, 1911), embodied in the high risk of R\&D (and the financing difficulties (Lee \& Cin, 2010). However, the government can achieve pareto optimal (Romer, 1990) with financial subsidy and incentives (Arrow, 1962). Financial subsidy has a significant impact on enterprise R\&D investment. Specifically, the effect has three acting ways including the incentive effect, crowding-out effect and inverted $U$ effect. In OECD countries, tax incentives and financial subsidy have the incentive effect on enterprise innovation (Guellec \& Pottelsberg 1997). In China, in the long-term (Xie et al., 2009) and short-term (Ding et al., 2007), the incentive ef- 
fect and crowding-out effect both exist (An et al., 2009). In general, it is more likely that there is a critical point of financial subsidy (Liu et al., 2012). The incentive effect and crowding-out effect are divided into two stages, that is, the impact of financial subsidy on enterprise R\&D is non-linear (Li et al., 2013).

Enterprises in different lifecycles have different attitudes towards R\&D and innovation. Lifecycle theory originated from biology as a theory of the evolution and growth of living organisms (Gross \& Haire, 1960). From the perspective of enterprise lifecycle theory, enterprises in the start-up period are faced with such adverse factors as financing constraints, innovation risks and incomplete business models (Liu, 2010). Therefore, their most important problem is survival. In the growth period, enterprises mainly face the problem of expansion, and R\&D investment can produce the largest incentive effect (Liang et al., 2010). In mature period, enterprises have abundant capital and stable market. They are mainly faced with the problem of how to maintain their market position and seek social value. Therefore, financial subsidy still has a strong incentive effect. During the decline stage, the resource input of enterprises is reduced and the demand for innovation is small (Yu, 2018). When enterprises are in different lifecycles, the influence of financial subsidy on their R\&D activities may be linear or inverted u-shaped (Xiong et al., 2016).

At present, most scholars still support the incentive effect brought by financial subsidy, that is, financial subsidy positively promotes enterprise innovation. Enterprise innovation has the characteristics of high investment, long payback period, high risk and so on. Often, the government provides financial subsidy for key scientific research projects with high risk and high investment, so that enterprise R\&D can make further progress and the total supply of social innovation can be further improved. From the perspective of enterprise lifecycle, most of the current papers have discussed the heterogeneity of enterprises in different lifecycles, as well as their different strategies in R\&D activities, which all will affect the effect of financial subsidy on enterprise innovation. Under the unique economic environment in China, this paper focuses on the impact of financial subsidy on listed enterprises in China, and whether there are differences in the impact on enterprises in different lifecycles. The research question in this paper is whether China's financial subsidy has an impact on enterprise R\&D. If exist, whether financial subsidy has the same impact on enterprises in different lifecycle stages. Research objectives in this paper are as follows.

First, this paper wants to prove that financial subsidy has an incentive effect on enterprise R\&D investment. Enterprise innovation faces many uncertainties and risks. Most companies have limited capital. Due to large capital investment and a long recovery cycle, it will be very difficult for enterprises to complete R\&D activities independently without effective financial subsidy. The presence of imitators and free learners in the market has further eroded these innovators' $\mathrm{R} \& \mathrm{D}$ revenues. In turn, $\mathrm{R} \& \mathrm{D}$ costs will rise. In this case, financial subsidy can bear part of the R\&D costs, reduce the pressure of enterprises, improve the environment faced by enterprises, and partly make up for the losses caused by ex- 
ternalities. The above effects of financial subsidy can reduce the threshold for enterprises to carry out R\&D. Therefore, financial subsidy will have a significant incentive effect on enterprise R\&D investment.

Second, this paper aims to prove that the effects of financial subsidy on enterprises in different lifecycles are heterogeneous. Enterprises in different lifecycles have significant differences in cash flow, innovation ability, financial status and business strategy. Most scholars divide enterprise lifecycle into four stages: initial stage, growth stage, mature stage and decline stage. Because most of the listed enterprises have passed the initial stage, this paper does not take the initial stage into account in the process of dividing the enterprise lifecycle.

\section{Literature Review}

The influence path of financial subsidy on enterprise R\&D can be divided into incentive effect, extrusion effect and inverted u-shaped effect. In general, financial subsidy can promote enterprises' investment in R\&D. For enterprises in different lifecycles, the innovation attitude of enterprises in growth and maturity periods is far more positive than that of enterprises in decline period.

\subsection{Relationship between Financial Subsidy and Enterprise Innovation}

Schumpeter (1911) first proposed the concept of creative destruction, indicating that the core of the transformation of economic momentum comes from enterprise innovation, which is what we call innovation-driven economic development. However, since the market cannot spontaneously balance the supply and demand of social innovation, the property of public goods of enterprises R\&D will lead to market failure. Therefore, the research on financial subsidy appears. Arrow (1962) first began studying the financial subsidy and enterprise R\&D. He proposed that the externalities of enterprise innovation would lead to the mismatch between R\&D's benefits and costs. If only relying on the market, enterprise $R \& D$ investment will be insufficient and lower than the optimal level required by the society. Lee and Cin (2010) studied the necessity of financial subsidy to stimulate innovation in start-up and growth enterprises. They believed that enterprises in the mature stage have positive cash flow and have occupied a certain market share, thus they have enough capital to carry out R\&D to provide momentum for the development of enterprises. However, enterprises in the start-up and growth period will face financing difficulties, and they have little capital, small market share and insufficient resources. Without the intervention of financial subsidy, it will be difficult for these enterprises to improve their competitiveness through $\mathrm{R} \& \mathrm{D}$. At the same time, financial subsidy can also represent a good signal for the company to attract external capital.

\subsection{The Influence Path of Financial Subsidy on Enterprise Innovation}

There are three main conclusions about the influence of financial subsidy on en- 
terprise innovation. First, financial subsidy has incentive effect. Second, financial subsidy has crowding out effect. Third, the effect is of inverted U shape.

In terms of incentive effect, Guellec \& Pottelsberg (1997) studied 15 years' data of OECD countries through panel regression. He found that tax incentives and financial subsidy had incentive effects on enterprise innovation, and there was threshold of incentive, that is, the effect of financial subsidy presented an inverted u-shaped curve. Then he compared the effects of tax incentives and financial subsidies on enterprise innovation and found that the incentive effect of direct financial subsidy was higher than that of tax incentives. Ding et al. (2007) analyzed the panel data of provincial enterprises and proved that financial subsidy had a significant positive incentive effect on enterprise innovation input. Xu and $\mathrm{Fu}$ (2018) selected the agricultural sector from the listed companies to build a set of indicators for R\&D investment and corporate performance, and conducted a comprehensive rating. They found that financial subsidy had a significant incentive effect on enterprises' R\&D investment, and the effect decreased with the increase of enterprises' survival time.

Proponents of crowding out effect argue that financial subsidy will crowd out some of the R\&D investment that enterprises ought to spend. Because enterprises are more inclined to invest in projects supported and subsidized by the government, and at the same time reduce the investment in projects that do not receive subsidy, resulting in crowding out effect. Yu (2009) built a production function model based on the data of Shandong's R\&D investment from 1996 to 2006 , and found that the financial subsidy would produce crowding out effect on enterprise innovation. Lichtenberg (1998) and David, Hall (2000) also obtained the same results.

It is proposed that there is a critical point in the influence curve. In the initial stage of financial subsidy, subsidy has an incentive effect on enterprises' $R \& D$ investment. After passing the critical point, financial subsidy can produce crowding out effect. Liu (2012) believes that there is a critical point between financial subsidy and enterprises' $R \& D$ investment. This critical point divides the effect of financial subsidy on enterprises' $R \& D$ investment into incentive effect and crowding out, that is, the effect is non-linear and presents the characteristics of inverted u-shaped curve. Li and Bai (2013) established a threshold effect model, proving that financial subsidy has a threshold, and also proving that other relevant factors such as enterprise size and industrial technology level also have a threshold effect on enterprises' R\&D investment.

\subsection{The Innovative Attitude of Enterprises in Different Lifecycles}

The lifecycle theory has its roots in biology. It is a theory about the evolution and growth of living things. It mainly describes the different characteristics of a living thing from birth to death.

(Gross \& Haire, 1960) was the first to discover that there are similar characteristics between enterprises and living things, and proposed the term enterprise lifecycle. Since then, scholars began to study enterprise innovation and enter- 
prise behavior from the perspective of biology. Papers generally divide the enterprise lifecycle into four stages, all of which have unique characteristics. Therefore, enterprises in different stages often adopt different strategies. Liu (2010) believes that enterprises in the start-up period are faced with financing constraints, innovation risks, incomplete business models and other adverse factors, so their most important problem is survival. Enterprises in the growth period are mainly faced with the problem of expansion. Liang et al. (2010) introduced the theory of enterprise life cycle when studying the impact of enterprise innovation input on performance, and found that R\&D investment of enterprises in the growth stage produced the largest incentive effect. Enterprises in the mature stage have formed scale advantages, abundant funds and stable market shares, and they are mainly faced with the problem of how to maintain market position and seek social value. Yu (2018) believes that enterprises in the decline stage will be in this situation: resource input decreased, the product market shrink, the market share declined, the cash flow decreased greatly and the financing capacity decreased. Therefore, enterprises in the decline period are mainly faced with how to transform and exit.

\section{Data and Methodological Framework}

\subsection{The Regression Model}

This paper mainly discusses the incentive effect and heterogeneity of financial subsidy on enterprise R\&D. However, there are many factors that affect enterprise $R \& D$, such as enterprise size and profitability (Chen et al., 2019). Enterprise $R \& D$ also has a strong individual effect, and will change with the macroeconomic changes in different periods. On the basis of the above, the individual fixed effect model is established as follows.

$$
\text { rdintensity }=\beta_{0} \text { subsidy }+\sum \beta_{i} X_{i, t}+\mu_{i}+\omega_{t}+\varepsilon_{i, t}
$$

$X_{i, t}$ is the control variable, including the duration of the enterprise, enterprise size, economic output, capital structure, profitability and other variables. $\mu_{i}+\varepsilon_{t}$ is the complex disturbance term of the fixed effect model. $\mu_{i}$ is the intercept term representing individual heterogeneity. $\omega_{t}$ represents the disturbance term of all enterprise changes at the time level. Therefore, the model considers both time and individual fixed effects.

\subsection{Description of Variables}

The explained variable was the intensity of R\&D expenditure (named "RDintensity"), defined as R\&D expenditure divided by total assets. R\&D investment and output must be included in the annual report of listed companies. In order to present the model results more intuitively, this paper takes the total assets of the enterprise at the end of the period as the denominator, and the R\&D expenditure disclosed in the annual report as the numerator for measurement.

The explanatory variable is the financial subsidy intensity (named "subsidy"), defined as the financial subsidy divided by the total assets. Financial subsidy 
mainly includes capital subsidy and other non-capital subsidies such as government purchase and tax incentives. This paper chooses capital subsidy to measure the amount of financial subsidy. The ratio between the amount of capital subsidy and the total assets of the enterprise is taken as the explanatory variable.

In this paper, the logarithm of the total assets of the enterprise at the end of the period, the duration of the enterprise, earnings per share, net profit, profitability, ROA, per capita capital and other indicators (shown in Table 1) are selected as control variables to reduce the impact of missing variables on the accuracy of the model.

\subsection{Data Selection and Processing}

The research object of this paper is mainly listed enterprises in Shanghai and Shenzhen stock exchanges. The data are mainly from the database of WIND and CSMAR. Listed companies are chosen because the operational and financial data of listed companies are more stable than that of unlisted companies, and their $\mathrm{R} \& \mathrm{D}$ status is more representative in the industry. This paper selects data from the annual reports of listed companies from 2013 to 2017, and deals with the data as follows.

First, the listed companies are excluded.

Second, ST, ${ }^{\star} \mathrm{ST}$ and PT enterprises are excluded. Because these enterprises often have some operating problems and financial indicators are abnormal.

Third, due to the unique financial characteristics of financial enterprises, which are different from general listed enterprises, financial listed enterprises are excluded in this paper.

Fourth, the observations with obvious errors are excluded, such as net profit margin greater than 1 .

Table 1. Main variables.

\begin{tabular}{|c|c|c|c|}
\hline & Name & Symbols & Definition \\
\hline \multirow[t]{2}{*}{ Explained variable } & $\begin{array}{l}\text { intensity of } \\
\mathrm{R} \& \mathrm{D} \text { expenditure }\end{array}$ & rdintensity & $\mathrm{R} \& \mathrm{D}$ expenditure $\div$ total assets \\
\hline & financial subsidy & subsidy & capital subsidy $\div$ total assets \\
\hline \multirow[t]{4}{*}{ Explanatory variable } & enterprise lifecyle & lifecycle & $\begin{array}{l}\text { The enterprise lifecycle is divided by the } \\
\text { combination of cash flow indicators. }\end{array}$ \\
\hline & $\begin{array}{l}\text { duration of the } \\
\text { enterprise }\end{array}$ & age & $\begin{array}{l}\text { Business registration date } \\
\text { from the current time }\end{array}$ \\
\hline & enterprise size & size & $\log$ of total assets \\
\hline & output & roa & net profit $\div$ total assets \\
\hline \multirow[t]{4}{*}{ Control variables } & per capita capital & $\mathrm{lk}$ & Retained earnings $\div$ total staff \\
\hline & net profit & profit & log of absolute net profit \\
\hline & growth & growth & $\begin{array}{l}\text { (current year revenue - last year } \\
\text { revenue) } \div \text { last year revenue }\end{array}$ \\
\hline & profitability & EPS & earnings per share \\
\hline
\end{tabular}


Fifth, companies with incomplete key data are excluded.

In this paper, 7041 non-equilibrium panel data are obtained, which are processed and analyzed by Stata 15.0 and the descriptive statistics of main variables are shown in Table 2.

\section{The Empirical Analysis}

\subsection{Samples}

Combined with the existing theories to define the cash flow of enterprises in different lifecycles, this paper uses the cash flow grouping method to divide the lifecycle of samples. As listed companies have generally passed the initial period, so the division will not take the initial period into account. The sample enterprises are divided into growth period, mature period and decline period. The distribution of sample enterprises is shown in Table 3.

\subsection{Regression Results}

The unit root test and co-integration analysis are carried out. Since the data belong to the short-term non-equilibrium panel and the data have many missing values and poor continuity, the data can be approximately considered as sectional data without unit root or co-integration problem. The regression results of the fixed effect model are shown in Table 4.

Table 4 provides the results of the regression. In general, financial subsidy has a strong influence on enterprise $\mathrm{R} \& \mathrm{D}$, which proves the hypothesis that financial subsidy has an incentive effect on enterprise $R \& D$ input. As for the heterogeneity of influence, first of all, it can be found from the observations that the number of enterprises in the growth stage is basically equal to the number of enterprises in the maturity stage, which reflects the gradual transition from the emerging capital market to a more mature capital market in China. Secondly, financial subsidy has a significant impact on the R\&D intensity of enterprises in the growth and maturity stage, and the absolute coefficient of growth stage is greater

Table 2. Descriptive statistics of main variables.

\begin{tabular}{ccccc}
\hline Variables & Mean & Standard Deviation & Minimum & Maximum \\
\hline RD intensity & 0.05 & 0.05 & 0.00 & 0.89 \\
Subsidy & 0.01 & 0.17 & 0.00 & 16.47 \\
EPS & 0.50 & 0.62 & -0.20 & 21.56 \\
ROA & 6.82 & 0.07 & -10.90 & 32.30 \\
Size & 21.83 & 1.35 & 18.20 & 28.51 \\
Profit & 18.64 & 1.42 & 10.34 & 24.71 \\
Growth & 0.29 & 2.93 & -0.86 & 251.21 \\
Age & 15.62 & 5.52 & 1.00 & 61.00 \\
lk & 0.06 & 0.07 & -2.00 & 2.60 \\
\hline
\end{tabular}

Data sources: WIND, CSMAR. 
Table 3. Lifecycle distribution of listed companies from 2013 to 2017.

\begin{tabular}{ccccc}
\hline Year & Lifecycle & Growth Period & Mature Period & Decline Period \\
\hline \multirow{2}{*}{2013} & Number & 444 & 589 & 156 \\
& Percentage & $37.34 \%$ & $49.54 \%$ & $13.12 \%$ \\
2014 & Number & 459 & 559 & 240 \\
& Percentage & $36.49 \%$ & $44.44 \%$ & $19.08 \%$ \\
2015 & Number & 779 & 749 & 226 \\
& Percentage & $44.41 \%$ & $42.70 \%$ & $12.88 \%$ \\
2016 & Number & 995 & 939 & 245 \\
& Percentage & $45.66 \%$ & $43.09 \%$ & $11.24 \%$ \\
2017 & Number & 1079 & 821 & 269 \\
& Percentage & $49.75 \%$ & $37.85 \%$ & $12.40 \%$ \\
\multirow{2}{*}{ Total } & Number & 3756 & 3657 & 1136 \\
& Percentage & $43.93 \%$ & $42.78 \%$ & $13.29 \%$ \\
\hline
\end{tabular}

Table 4. Effects of financial subsidy on enterprise R\&D intensity: full sample regression results.

\begin{tabular}{ccccc}
\hline RD Intensity & (1) Total & (2) Growth Period & (3) Mature Period & (4) Decline Period \\
\hline Subsidy & $0.05006^{* * *}$ & $0.38359^{* * *}$ & $0.16043^{* * *}$ & -0.28460 \\
EPS & 0.00032 & -0.00068 & -0.00003 & -0.04205 \\
ROA & $-0.00074^{* * *}$ & $-0.00080^{* * *}$ & $-0.00053^{* * *}$ & 0.00354 \\
Size & $-0.00415^{* * *}$ & -0.00523 & -0.00231 & 0.09077 \\
Profit & $0.00167^{* * *}$ & $0.00314^{* * *}$ & 0.00056 & -0.02716 \\
Growth & $-0.00013^{*}$ & -0.00010 & 0.00006 & -0.02570 \\
Age & -0.00013 & 0.00037 & -0.00044 & $-0.00981^{\star}$ \\
lk & $0.04441^{* * *}$ & $0.17609^{* * *}$ & $0.15411^{* * *}$ & 0.54083 \\
N & 9814 & 3756 & 3657 & 1136 \\
F-statistic & 3.52 & 1.47 & 2.25 & 3.14 \\
R-squared & 0.36 & 0.13 & 0.31 & 0.95 \\
\hline
\end{tabular}

${ }^{*}$ Significant at $10 \%$ level of significance. ${ }^{*}$ Significant at $5 \%$ level of significance. ${ }^{* *}$ Significant at $1 \%$ level of significance.

than that in the maturity stage. This finding further demonstrates the strong heterogeneity of the effect of financial subsidy on enterprise R\&D investment. To be specific, enterprises in the growth stage have strong $R \& D$ willingness and low $R \& D$ ability; enterprises in the mature stage have strong $R \& D$ willingness and high ability; enterprises in the decline stage have weak R\&D willingness and low ability.

As for the influence of control variables on enterprise R\&D investment, this paper draws the following conclusions. 
First, enterprises in different life cycles have different effects on R\&D investment. Because enterprises in the decline stage enter the phase of obsolescence as their survival time increases, and they tend to choose delisting or liquidation and acquisition, resulting in a large-scale reduction in R\&D investment. Overall, the effect of duration is not significant. Therefore, if only relying on the enterprise survival time to divide the enterprise lifecycle, there will be a certain error.

Second, enterprise net profit has a significant positive impact on R\&D investment. As net profit increases, cash flows increase so enterprises have more money to spend on R\&D.

Third, the growth of enterprise has a significant inhibitory effect on the enterprise $\mathrm{R} \& \mathrm{D}$ investment. This may be due to the fact that in order to maintain the speed of development, enterprises with rapid growth will choose to devote most of their resources to developing markets and earning profits, while reducing the investment in $\mathrm{R} \& \mathrm{D}$ which has high risks and strong uncertainties.

Fourth, the per capita capital of enterprise has a significant positive impact on enterprise R\&D investment. Enterprise s with more capital per person may be in capital-intensive or technology-intensive industries, so they have a better chance of turning more R\&D into output.

Fifth, the overall impact of enterprise size on $R \& D$ investment is significantly negative, but the impact is not significant under grouping regression. This may be because the stability of grouping data is not good, and hidden variables between groups have a great impact on enterprises $R \& D$ investment, leading to unstable grouping regression.

\subsection{Robustness}

The above is the result of regression of static non-equilibrium panel data. However, in the process of analyzing the influence of control variables, we find that there may be missing variables. In particular, the individual competence of entrepreneurs may be a missing variable, since competent entrepreneurs can get more subsidies through their business networking and influence. This index is not easy to calculate, but it has a strong correlation with the financial subsidy received by enterprises, which may cause the endogenous problem.

To solve this problem, we need to find an indicator that is not only related to the individual ability of entrepreneurs, but also irrelevant to the financial subsidy received by enterprises. In this paper, the average financial subsidy of the province (excluding the sample enterprise) where the sample enterprise is located is selected as the instrumental variable. Firstly, in terms of correlation, entrepreneurs in different regions have different business networking and influence, so the selected instrumental variable is related to entrepreneurs' personal ability. Secondly, in terms of exogenous, financial subsidy obtained by other enterprises have nothing to do with financial subsidy obtained by their own enterprises, that is, the selected instrumental variable is exogenous. After selecting appropriate instrumental variable, we carry out two-stage least square regression (results shown in Table 5) and find that conclusions stay the same. 
Table 5. 2SLS results of the instrumental variable.

\begin{tabular}{ccccc}
\hline RD Intensity & (1) Total & (2) Growth Period & (3) Mature Period & (4) Decline Period \\
\hline Subsidy & $0.02^{*}$ & $0.26^{* *}$ & $0.14^{*}$ & -0.37 \\
N & 9814 & 3756 & 3657 & 1136 \\
Wald F-statistic & 169.46 & 88.60 & 80.50 & 3.95 \\
\hline
\end{tabular}

${ }^{*}$ Significant at $10 \%$ level of significance. ${ }^{*}$ Significant at $5 \%$ level of significance.

\subsection{Findings}

The following conclusions can be drawn by analyzing the data of China's A-share market from 2013 to 2017. Firstly, the fixed effect model is used to carry out regression, and it is found that financial subsidy has a positive incentive effect on enterprise $\mathrm{R} \& \mathrm{D}$. Then the results are discussed in layers, and it can be found that the effects of financial subsidies are different for enterprises in different lifecycles. Financial subsidy has the strongest positive incentive effect on enterprises in the growth stage, followed by the maturity stage, and does not generate positive incentive in the recession stage.

\section{Conclusion}

This paper firstly analyzes recent researches on the influence of financial subsidy on enterprise innovation and innovation attitudes of enterprises in different life cycles. Based on this, it is speculated that the financial subsidy will have different effects on the innovation of enterprises in different lifecycles. After the theoretical analysis and empirical analysis, the following conclusions are drawn.

First, enterprise R\&D needs financial subsidy to reach the level of social needs. Enterprise R\&D has externalities, risks and the attribute of public goods. These characteristics make it difficult for enterprises to spontaneously achieve the level of social demand. Therefore, the government needs to get involved in technological innovation, especially use financial subsidy to compensate enterprises for their R\&D difficulties, so as to encourage enterprises to carry out technological innovation. The empirical results show that financial subsidy can effectively compensate the innovation risk of enterprises, reduce the innovation cost and innovation threshold, increase enterprises' investment in R\&D, and help enterprises to bear the uncertain risks.

Second, the incentive effect of financial subsidy varies with the development of enterprise lifecycle. Enterprises can be divided into initial stage, growth stage, mature stage and decline stage. The financial subsidy efficiency varies for enterprises in different stages. This paper proves that financial subsidy has an incentive effect in the growth and mature stage, but the incentive effect on enterprises in the growth stage is larger, which also conforms to the results of theoretical analysis. In the stage of market expansion, enterprises need $R \& D$ and innovation to form differentiated competition, so the demand for R\&D increases. However, most of the enterprises in the mature stage have been in a monopoly position, occupying a higher market share, which results in low willingness to innovate. In 
addition, financial subsidiy has no significant incentive effect on R\&D of enterprises in the decline stage. Because of the declining product competitiveness and market share, slow equipment update and financial risks, most of enterprises in the decline stage will make up for their existing difficulties after receiving financial subsidy, instead of using the funds for $\mathrm{R} \& \mathrm{D}$ and innovation to enhance long-term value.

\section{Conflicts of Interest}

The authors declare no conflicts of interest regarding the publication of this paper.

\section{References}

An, T. L., Zhou, S. D., \& Pi, J. C. (2009). The Incentive Effect of R\&D Subsidy on Independent Innovation of Chinese Enterprises. Economic Research, 10, 87-98.

Arrow. (1962). Economic Welfare and the Allocation of Resource for Invention in National Bureau of Economic Research. Princeton, NJ: Princeton University Press.

Chen, H., Zhang Y., \& Liu, D. X. (2019). Government Subsidy, Tax Preference and Enterprise Innovation Performance-Empirical Study of Different Lifecycle Stages. Nankai Management Review, 22, 187-200.

David, P. A., \& Hall, B. H. (2000). Heart of Darkness: Modeling Public-Private Funding Interactions Inside the R\&D Black Box. Research Policy, 29, 1165-1183. https://doi.org/10.1016/S0048-7333(00)00085-8

Ding, X. Y., Pan, S. B., \& Yu, H. N. (2007). The Impact of Government R\&D Expenditure on Zhejiang Business R\&D Activities. Studies in Science, 25, 248-253.

Gross, E., \& Haire, M. (1960). Modern Organization Theory: A Symposium of the Foundation for Research on Human Behavior. Industrial and Labor Relations Review, 113, 663. https://doi.org/10.2307/2520235

Guellec, D., \& Pottelsberg, B. (1997). Does Government Support Stimulate Private R\&D? OECD Economic Review, 29, 2.

Lee, E. Y., \& Cin, B. C. (2010). The Effect of Risk-Sharing Government Subsidy on Corporate R\&D Investment: Empirical Evidence from Korea. Technological Forecasting \& Social Change, 77, 881-890. https://doi.org/10.1016/j.techfore.2010.01.012

Li, R. Q., \& Ba, J. H. (2013). The Effect of Government R\&D Subsidies on Enterprise Technology Innovation: An Empirical Research Based on Threshold Regression. Economic Issues in China, 3, 11-23.

Liang, L. X., Jin, Y., \& Zhao, N. (2010). Study on the Relationship between R\&D and Enterprise Performance Based on Enterprise Life Cycle: Empirical Research in Listed Firm. Science and Management of S.\&T, 31, 11-17.

Lichtenberg, F. R. (1988). Assessing the Impact of Federal Industrial R\&D Expenditure on Private R\&D Activity in the United States. Berlin: Springer Netherlands.

Liu, H. (2012). Analysis of the Impact of New Accounting Standards on Enterprise Financial Management. New Finance and Economics, 10, 307

Liu, H., Xiao, M. F., \& Tang, Q. Q. (2012). Incentive and Crowding-out Effects of R\&D Subsidy on Companies' R\&D Expenditures-Empirical Analysis Based on the Data of Chinese Listed Companies. Economic Management, 34, 19-28.

Liu, Y. Y. (2010). Study on the Tactics of Strategic Innovation of SMEs Based on the Life 
Cycle Perspective. Enterprise Vitality, 83-87.

Romer, P. M. (1990). Are Nonconvexities Important for Understanding Growth? American Economic Review, 80. https://doi.org/10.3386/w3271

Schumpeter, J. A. (1911). The Theory of Economic Development. Cambridge, MA: Harvard University Press.

Xie, W. M., Tang, Q. Q., \& Lu, S. S. (2009). Government R\&D Subsidy, Enterprise R\&D Expenditure and Independent Innovation-Empirical Evidence from Chinese Listed Companies. Financial Research, 6, 86-99.

Xiong, H. P., Yang, Y. J., \& Zhou, L. (2016). Effects of Government Subsidies on R\&D on Enterprises with Different Lifecycles. Science and Management of Technology, 37, 3-15.

Xu, M. L., \& Fu, F. Y. (2018). The Impact of Government Subsidies and R\&D Investment on Enterprise Performance: An Empirical Study Based on Agricultural Listed Companies. Financial Research, 3, 62-65.

Yu, K. (2018). Study of Classification Shifting Earnings Management Based on Corporate Lifecycle: Empirical Evidence from Chinese Listed Companies of Manufacturing. Journal of Hunan University of Science \& Technology, 33, 102-108.

Yu, Y. X. (2009). Empirical Research on the Impact of Government R\&D Investment on Enterprise R\&D Investment. Dong Yue Forum, 30, 97-99. 